\title{
Modeling the Stem Elongation Response of Poinsettia to Chlormequat
}

\author{
P.R. Fisher ${ }^{1}$ and R.D. Heins \\ Department of Horticulture, Michigan State University, East Lansing, Michigan 48824
}

J.H. Lieth

Department of Environmental Horticulture, University of California, Davis, California 95616

\begin{abstract}
Additional index words. Euphorbia pulcherrima, plant growth, height control, dose response, growth retardant, plant growth regulator, three-phase function, Richards function, simulation

Abstract. Stem elongation response to a single foliar application of the growth retardant chlormequat chloride [(2chloroethyl) trimethylammonium chloride] for poinsettia (Euphorbia pulcherrima Klotz.) was quantified. Growth retardant applications did not affect final leaf count or timing of visible bud, first bract color, or anthesis. There was a statistically significant effect of growth retardant concentration on stem elongation, with a range from $289 \pm 15 \mathrm{~mm}(\mathrm{mean}$ $\pm 95 \%$ confidence intervals) for the control plants to $236 \pm 17 \mathrm{~mm}$ at $4000 \mathrm{ppm}$. The growth-retarding effect during the first day after the application was not significantly different between 500 and $4000 \mathrm{ppm}$, and concentration primarily affected the duration of growth-retarding activity. A dose response function was incorporated into a three-phase mathematical function of stem elongation of single-stem poinsettia to predict elongation of treated and untreated plants. The model was calibrated using a data set from plants receiving $0,500,1000,1500,2000,3000$, and $4000 \mathrm{ppm}$, with a resulting $R^{2}$ of 0.99 . Validation of the dose response model against an independent data set resulted in an $r^{2}$ of 0.99 , and predicted final stem length was within $12 \mathrm{~mm}$ of observed final length.
\end{abstract}

A three-phase mathematical function has been used to model shoot elongation of single-stem poinsettia (Euphorbia pulcherrima Klotz.) (Fisher et al., 1996). In calibrating the model, aside from nyctoperiod and minor greenhouse temperature fluctuations, environmental factors were constant throughout the experiment. For a stem elongation model to be useful for simulation and practical application, however, it is necessary to incorporate the effect of perturbations such as growth retardant applications and temperature effects. Growth retardant chemicals are used widely in the commercial production of poinsettia and other flowering potted plants for height control (Ecke et al., 1990). A simulation model may be a useful horticultural tool because there is increasing pressure to minimize the use of growth retardants (Ludolph, 1992) and maximize their efficacy.

Although many researchers have examined the impact of growth retardant applications on poinsettia final height and flowering (for example, Holcomb et al., 1992; Holcomb and Rose, 1992; Larson, 1967; McDaniel, 1986; McDaniel and Wilson, 1990), published data are not suitable for predicting short term changes in stem elongation rate. These data provide a basis for determining the effects of growth retardant type and concentration on final plant height. It is difficult to generalize these results, however, because growth retardant efficacy can be affected by a range of environmental conditions, including soil media composition (Barrett, 1982), timing (Gilbertz, 1992), nutrient status, application technique and frequency, chemical type, concentration, and temperature (Larson, 1967).

The objectives of this project were to quantify the dose response of poinsettia to a single foliar application of chlormequat chloride growth retardant [(2-chloroethyl) trimethylammonium chloride]

Received for publication 7 Aug. 1995. Accepted for publication 7 Mar. 1996. We thank University Outreach at Michigan State Univ. for providing funding for this project. The cost of publishing this paper was defrayed in part by the payment of page charges. Under postal regulations, this paper therefore must be hereby marked advertisement solely to indicate this fact.

${ }^{1}$ Current address: Dept of Environmental Horticulture, Univ. of California, Davis, CA 95616 and incorporate the dose response into a three-phase model of stem elongation $\left(f_{\text {3-phase }}\right.$, Fisher et al., 1996). Separate data sets were collected for model calibration and validation. A methodology developed by Lieth and Reynolds (1986) for modifying the Richards function (Richards, 1959) to incorporate the effect of daminozide applications on chrysanthemum [Dendranthema grandiflora (Ramat.) Kitamura] was adapted to model a different chemical (chlormequat), species (poinsettia), and base function $\left(f_{3-\text { phase }}\right)$.

\section{Materials and Methods}

Modeling an environmental perturbation. In the Lieth and Reynolds (1986) approach, the Richards equation (Eq. [1]),

$\frac{d H_{u}}{d t}=\frac{k H_{u}\left(A^{n}-H_{u}^{n}\right)}{\left(n A^{n}\right)}$

with the solution (Eq. [2]), commonly termed the Richards function,

$H_{u}=\frac{H_{\mathrm{o}} A}{\sqrt[n]{H_{0}^{n}+\left(A^{n}-H_{0}^{n}\right) e^{-k t}}}$

was fitted to data from plants grown in constant conditions. In the Richards function, $t$ represents time, $A$ defines the upper asymptote of untreated plant height $H_{u}$, and parameters $H_{0}, n$, and $k$ determine the lower asymptote and shape of the growth curve with respect to $A$ (Table 1). The estimated values of $A, H_{0}, n$, and $k$ describe the asymptotic growth characteristics of $H_{u}$ in the absence of environmental change.

The Richards function was modified by Lieth and Reynolds (1986) to simulate the response to an environmental perturbation. The response function was termed $g(t)$, and the modified Richards equation was written as

$\frac{d H}{d t}=\frac{d H_{u}}{d t} g(t)$

where $g(t)$ is a function that has a value $\geq 0$. If $g(t)=0$, there is no growth, a $g(t)$ of 1 means that the treated plant grows at the same 
rate as a control plant, and a $g(t)<1$ or $>1$ would indicate that the treated plant is growing slower or faster than the control, respectively.

Larsen and Lieth (1993) modeled the dose response to daminozide by formulating two alternative $g(t)$ functions (Fig. 1, Eqs. [4] and [5]). A foliar spray application at time $t_{e v}$ was assumed to immediately reach a maximum effect, or amplitude, that declined over time. Before the spray application $\left(t<t_{e v}\right), g(t)$ had a value of 1 (no effect). After $t_{e v}, g(t)$ was a function that had a value less than 1 . When a linear decay function $\left(g_{L}(t)\right)$ was used, the chemical was assumed to have an immediate maximum effect $\left(M_{L}\right)$ that declined over a period termed persistence $\left(P\right.$, days) until $\mathrm{g}(\mathrm{t})=1$ at time $t_{\text {rec }}$. The linear model is represented below (Eq. [4]), and is represented graphically (Fig. 1a):

$g_{L}(t)= \begin{cases}1 & \ldots \text { for } t \leq t_{e v} \\ \left.M_{L}+\left[1-M_{L}\right) / P\right]\left(t-t_{e v}\right) & \ldots \text { for } t_{e v}<t \leq t_{r e c} \\ 1 & \text { for } t<t\end{cases}$
In the exponential decay curve $\left(g_{E}(t)\right.$, Eq. [5] and Fig. 1b), $M_{E}$ referred to the amplitude of the response and $C_{E}$ represented the rate of decay.

$g_{E}(t)= \begin{cases}1 & \text {.for } t \leq t_{\text {ev }} \\ 1-\left(1-M_{E}\right) e^{\left[-C_{E}\left(t-t_{e v}\right)\right]} & \text {.for } t>t_{\text {ev }}\end{cases}$

Larsen and Lieth (1993) obtained estimates of $A, n, H_{0}$ and $k$ in the Richards function by fitting Eq. [2] to data from untreated plants. The modified Richards function (Eq. [3]) was then fitted to data from the growth retardant-treated plants, requiring only the estimation of the $g(t)$ parameters, because the parameter estimates of $A, n, H_{0}$, and $k$ were fixed based on the untreated plants.

Three-phase methodology. The $f_{3 \text {-phase }}$ poinsettia stem elongation model for modeling elongation under constant temperature conditions and variable flower initiation dates is described in detail by Fisher et al. (1996). Equations were chosen (Eq. [6]) that provided the empirical qualities desired to develop a sigmoid curve. Increasing growth rate during the initial lag phase was

Table 1. List of abbreviations and parameters.

\begin{tabular}{|c|c|c|}
\hline Symbol & Description & Units \\
\hline $\bar{\alpha}$ & Initial stem length in the lag phase of $f_{3 \text {-phase }}$ & $\mathrm{mm}$ \\
\hline$\beta$ & Rate constant in lag phase of $f_{3 \text {-phase }}$ & per day \\
\hline$\gamma$ & Gradient of linear phase of $f_{3-\text { phase }}$ & $\mathrm{mm} \cdot \mathrm{d}^{-1}$ \\
\hline$\delta$ & Asymptotic potential growth during plateau phase of $f_{3-\text { phase }}$ & $\mathrm{mm}$ \\
\hline$\Delta t_{S V}$ & Time from $\mathrm{t}_{S}$ to $t_{V}$ & days \\
\hline$\Delta t_{V P}$ & Time from $t_{V}$ to $t_{P}$ & days \\
\hline$a$ & Parameter used to estimate duration or persistence of $g(t)$ & days \\
\hline$A$ & Asymptotic height parameter in the Richards function & $\mathrm{mm}$ \\
\hline$b$ & Parameter used to estimate duration or persistence of $g(t)$ & days/ppm \\
\hline$C_{E}$ & Recovery parameter in exponential $g_{E}(t)$ dose response function & per day \\
\hline Conc & Concentration of chlormequat & ppm \\
\hline$D$ & Duration parameter in exponential $g_{E}(t)$ dose response function (inverse of $C_{E}$ ) & days \\
\hline DIF & Average day minus average night temperature & ${ }^{\circ} \mathrm{C}$ \\
\hline$f_{3-p h a s e}$ & Three-phase stem elongation model & \\
\hline$f_{L A G}$ & Function during lag phase of $f_{3-\text { phase }}$ & \\
\hline$f_{L I N}$ & Function during linear phase of $f_{3-p h a s e}$ & \\
\hline$f_{P L A}$ & Function during plateau phase of $f_{3-p h a s e}$ & \\
\hline$g_{E}(t)$ & Exponential dose response function & \\
\hline$g_{L}(t)$ & Linear dose response function & \\
\hline$G_{E}$ & Complete stem elongation model incorporating $f_{3 \text {-phase }}$ and $g_{E}(t)$ & \\
\hline$G_{L}$ & Complete stem elongation model incorporating $f_{3 \text {-phase }}$ and $g_{L}(t)$ & \\
\hline$g(t)$ & Environmental perturbation function & \\
\hline$H$ & Predicted stem length & $\mathrm{mm}$ \\
\hline$H_{0}$ & Initial stem length parameter in the Richards function & $\mathrm{mm}$ \\
\hline$H_{f}$ & Predicted final stem length in $f_{3-\text { phase }}$ & $\mathrm{mm}$ \\
\hline$H_{u}$ & Predicted stem length of untreated plant & $\mathrm{mm}$ \\
\hline$k$ & Rate parameter in the Richards function & per day \\
\hline$k_{P L A}$ & Rate parameter in plateau phase & per day \\
\hline$M_{E}$ & Initial amplitude effect of exponential $g_{E}(t)$ dose response function & \\
\hline$M_{L}^{L}$ & Initial amplitude effect of linear $g_{L}(t)$ dose response function & \\
\hline$n$ & Point of inflection in the Richards function & \\
\hline$P$ & Persistence parameter in linear $g_{L}(t)$ dose response function & days \\
\hline$t$ & Time variable & days \\
\hline$t_{0}$ & Time of transplanting & days \\
\hline$t_{L}$ & Time when lag phase ends and linear phase begins in $f_{3 \text {-phase }}$ & days \\
\hline$t_{P}$ & Time when linear phase ends and plateau phase begins in $f_{3 \text {-phase }}$ & days \\
\hline$t_{e v}$ & Time of growth retardant application & days \\
\hline$t_{\text {rec }}$ & Time at which plant recovers from linear $g_{L}(t)$ dose response & days \\
\hline$t_{S}$ & Time when short days (flower-initiating nyctoperiods) begin & days \\
\hline$t_{V}$ & Time when visible bud occurs & days \\
\hline
\end{tabular}



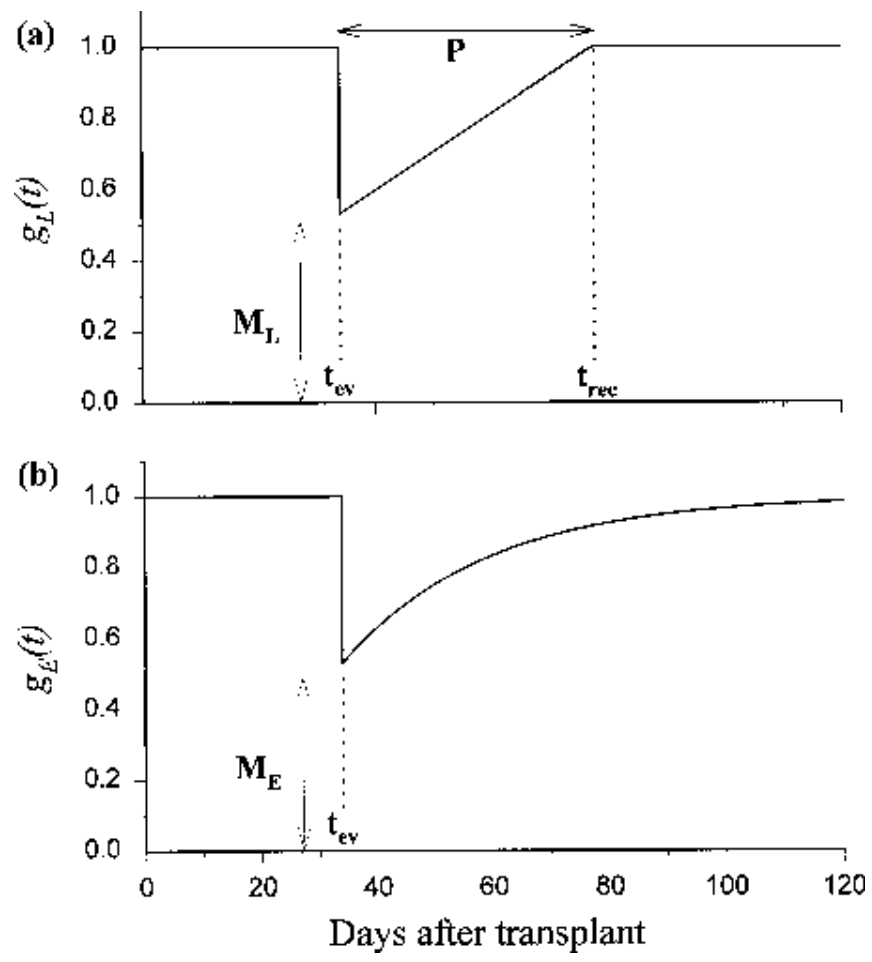

Fig. 1. Alternative $g(t)$ dose response models proposed by Larsen and Lieth (1993), where $g(t)$ represents the elongation rate of the treated plants relative to an untreated control. (a) a linear $g_{L}(t)$ model where the initial effect of a growth retardant application at time $t_{e v}$ is represented by $M_{L}$, and the declining growth retardant effect persists for $P$ days. (b) an exponential dose response model with declining growth retardant effect after an initial amplitude of $M_{E}$.

described with an exponential function $\left(f_{L A G}(t)\right)$, in which $\alpha(\mathrm{mm})$ is the observed starting length and $\beta$ (per day) is a rate constant. Constant growth rate during the linear phase was described with a linear function $\left(f_{L I N}(t)\right)$ with elongation rate $\gamma\left(\mathrm{mm} \cdot \mathrm{d}^{-1}\right)$. A monomolecular function $\left(f_{P L A}(t)\right)$ was used to describe decreasing elongation rate during the plateau phase, where the proportion of growth remaining when the plateau phase begins is represented by $\delta(\mathrm{mm})$, and $k_{P L A}$ (per day) represents the rate at which the plant reaches the asymptote.

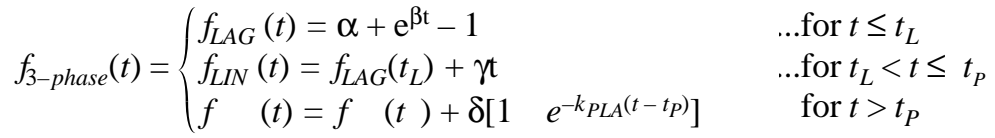

where the function and the first derivative were continuous at the transition points $\left(t_{L}\right.$ and $\left.t_{P}\right)$

$f_{L A G}\left(t_{L}\right)=f_{L I N}\left(t_{L}\right)$

$f_{L I N}\left(t_{P}\right)=f_{P L A}\left(t_{P}\right)$

$f_{L A G}^{\prime}\left(t_{L}\right)=f^{\prime}{ }_{L I N}\left(t_{L}\right)$

$f^{\prime} \quad(t)=f^{\prime} \quad(t)$

and the first derivative $f^{\prime}{ }_{3-p h a s e}$ is

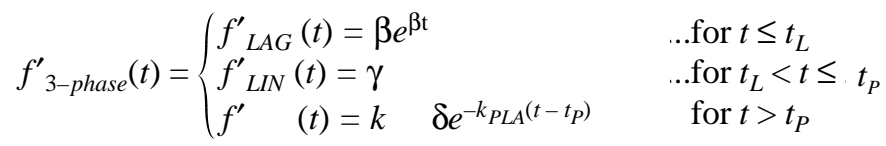

In the elongation model described by Fisher et al. (1996), $t_{p}$ was assumed to occur some number of days, $\Delta t_{V P}$, after the timing of visible bud $\left(t_{V}\right)$, because at $t_{V}$ the apical flower bud is visible and all internodes on the stem have begun to elongate. $t_{V}$ was in turn assumed to occur $\Delta t_{S V}$ days after the start of short days $\left(t_{S}\right)$ (when flower-initiating nyctoperiods begin). The model was therefore assigned parameters to estimate $\Delta t_{V P}$ and calculate $t_{P}$ based on the timing of visible bud:

$t_{P}=t_{v}+\Delta t_{V P}$

The $f_{\text {3-phase }}$ function (Eq. [6]) was fitted to data for control (untreated) plants to obtain a curve for elongation in the absence of a growth retardant application. The resulting model was then modified to incorporate the effect of a dose response function $g(t)$ on plant height $H$ by

$H=\int f^{\prime} 3-p h a s e(t) g(t) d t$

and

$$
\frac{d H}{d t}=\int f^{\prime} 3-\text { phase }(t) g(t)
$$

The parameters in the exponential dose response function $g_{E}(t)$ (Eq. [5]) were changed to create a new variable $D$ that was the inverse of $C_{E}$ :

$g_{L}(t)= \begin{cases}1 & \text {.for } t \leq t_{i v} \\ 1-\left(1-M_{E}\right) e^{\left[-\frac{1}{D}\left(t-t_{e v}\right)\right]} & \text {.ffor } t>t_{e v}\end{cases}$

By using the version of $g_{E}(t)$ in Eq. [12], high values of $P$ (Eq. [4]) and $D$ both indicated a slower recovery from the growth retardant (i.e., a greater duration of effect).

Experimental design for calibration data set. Rooted cuttings of 'Annette Hegg Dark Red' poinsettia were transplanted 17 Aug. 1994 into $15-\mathrm{cm}$-diameter $\left(1000-\mathrm{cm}^{3}\right)$ pots. Plants were grown in a Michigan State University (MSU, East Lansing) greenhouse at an average light integral of $11.7 \pm 2.7 \mathrm{~mol} \cdot \mathrm{m}^{-2} \cdot \mathrm{d}^{-1}$ (means are displayed \pm standard error unless otherwise stated), a daily temperature of $21.4 \pm 0.1^{\circ} \mathrm{C}$ and a DIF (average day minus average night) temperature of $0.9 \pm 0.1^{\circ} \mathrm{C}$. Night-interruption lighting was supplied from 2200 to $0200 \mathrm{HR}$ until 27 Sept. Black cloth was pulled from 1730 until 0800 HR from 27 Sept. until 25 Oct. after which plants were exposed to natural nyctoperiods.

A foliar spray of chlormequat (10 ml/plant) was applied with a hand sprayer to four sides of the plant to achieve thorough coverage. This spray volume ensured complete coverage of all leaf surfaces without runoff, although some spray drifted onto the media surface. Chlormequat was applied on 20 Sept., 34 days after transplanting, at six rates: 500, 1000, $1500,2000,3000$, and 4000 ppm plus an unsprayed control. Five plants per treatment were positioned randomly on a single subirrigated bench and were surrounded by untreated and unmeasured boundary plants. Plants were placed at $35 \times 35-\mathrm{cm}$ spacing to avoid light-quality effects from leaves overlapping between plants. Lateral shoots were removed every 2 weeks and plants were grown as single, i.e., unpinched, stems to facilitate height measurements. Height from the pot rim to the stem apex was measured twice weekly from transplanting until 1 week before application, daily from 1 week before application until 2 weeks after application, and twice weekly from 2 weeks after application until 2 weeks after anthesis. Leaf number was recorded weekly. Dates of first bract color (first color), externally visible flower buds (visible bud), and anthesis were recorded for each plant. 
Experimental design for validation data set. In a separate experiment at an MSU greenhouse during 1993, 40 rooted cuttings of 'Annette Hegg Dark Red' were planted in 15-cm-diameter pots on 20 Aug., and groups of 10 plants received chlormequat spray applications (10 ml/plant) at 0, 1000, 2000, or 3000 ppm 24 days after planting. Plants were not pinched, and lateral shoots were removed 15, 30, and 68 days after transplanting to leave a single stem. Night-interruption lighting was supplied until 36 days after transplanting, and was followed by 14-h nyctoperiods until anthesis. Average light integral was $11.3 \pm 2.5 \mathrm{~mol} \cdot \mathrm{m}^{-2} \cdot \mathrm{d}^{-1}$, and daily and DIF temperatures averaged $21.5 \pm 0.1^{\circ} \mathrm{C}$ and $-0.2 \pm 0.1^{\circ} \mathrm{C}$. Plants were subirrigated and grown at $35 \times 35-\mathrm{cm}$ spacing in a completely randomized design. Plant height to the stem apex and leaf count were recorded several times each week until anthesis and date of visible bud was also recorded.

Analysis. The $f_{3 \text {-phase }}$ model (Eq. [6]) was fitted to the control plants in the calibration experiment to obtain untreated estimates for $\beta, \gamma, \Delta t_{V P}$, and $\delta$ using PROC NLIN, the nonlinear regression procedure of SAS (SAS Institute, 1988). $\alpha$ was assigned the value of the observed transplant height for each plant.

Elongation from $t_{e v}$ until the end of the experiment was compared against growth retardant concentration using linear regression to confirm that increasing growth retardant concentration reduced elongation. The assumption in $g_{L}(t)$ and $g_{E}(t)$ functions that growth retardants had an immediate effect was tested using ANOVA to compare the growth rates of the treated and control plants between $t_{e v}$ and the first measurement date on $t_{e v}+1$. Effects of the chlormequat application on leaf unfolding rate and the time to first color, visible bud, and anthesis were compared by ANOVA to investigate whether development rate was affected in addition to stem elongation rate.

The $f_{3-\text { phase }}$ function (Eq. [6]) was fitted separately to data from each treatment between $t_{0}$ (time of transplanting) and $t_{e v}$ using SAS PROC NLIN, to estimate $\beta$ for each growth retardant treatment. Estimating $\beta$ by treatment did not affect predicted elongation rate after $t_{L}\left(\right.$ or $\left.t_{e v}\right)$, but accounted for random variation in initial elongation rate before $t_{L}$ and improved fitting of the dose response models. Parameters $\gamma, \Delta t_{V P}$, and $\delta$ were assumed to be equal to the parameter estimates for untreated control plants, and these estimates were entered as constants in the model.

Computation of $H$ using Eq. [10] required a numerical simulation procedure that used a rectilinear integration method with an integration interval of 0.5 days. The resulting data set of predicted $H$, using parameters for $\gamma, \Delta t_{V P}$, and $\delta$ from control plants and the estimates of $\beta$ by treatment, was used to estimate $g(t)$ parameters for each concentration. The $g(t)$ parameter estimates were graphed and a function was fitted to these data to estimate the dose response as a function of concentration. The $f_{3-\text { phase }}$ control parameters were combined with the $g_{L}(t)$ and $g_{E}(t)$ dose response functions to derive complete models, termed $G_{L}$ and $G_{E}$ respectively, for the elongation of single-stem poinsettia beginning at time of transplanting $\left(t_{0}\right)$. A simulation program with a time step of 0.5 days was used to generate data sets of predicted heights from both models. Goodness of fit of the predicted heights against the entire observed data set, including treated and untreated plants, was then quantified.

Finally, the model was validated against the 1993 data set. The $f_{3-}$ phase model (Eq. [6]) was fit to the control plants in the validation experiment to obtain untreated estimates for $\beta, \gamma, \Delta t_{V P}$, and $\delta$ using PROC NLIN, and $\alpha$ was assigned the value of the observed transplant height for each plant. Predicted heights were obtained by simulation of the $g(t)$ models from the calibration experiment combined with the untreated elongation curve to form $G_{L}$ and $G_{E}$ models for the validation data set. Predicted heights from the $G_{L}$ and $G_{E}$ model were then compared for goodness of fit against the observed height.

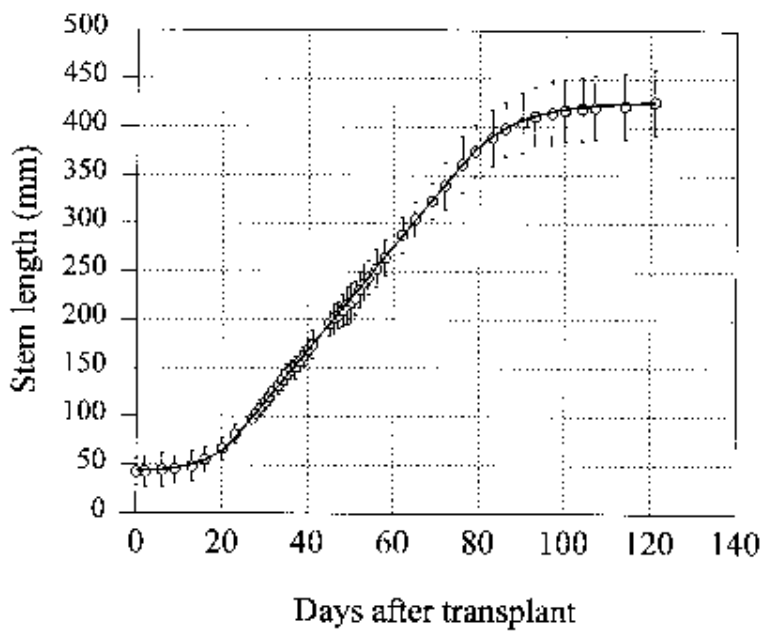

Fig. 2. Plot of observed and predicted average stem length over time for the untreated plants during the calibration experiment: $\bigcirc=$ mean observed height \pm $95 \%$ confidence intervals, solid line $=$ fit of the $f_{3-\text { phase }}$ function.

\section{Results}

Fitting the $f_{\text {3-phase }}$ function to control data. Elongation followed a three-phase pattern (Fig. 2), with an initial lag in elongation followed by a near-linear period of growth and a final plateau stage. Fitting the $f_{3-p h a s e}$ function to the height of untreated control plants resulted in an $R^{2}$ of 0.996 (Fig. 2, Table 2). Final height $\left(H_{f}\right)$, including the transplant height $(\alpha)$, was estimated to be $426 \mathrm{~mm}$, equal to the observed final height of $426 \pm 17 \mathrm{~mm}$. Plants were estimated to begin the linear phase of elongation 23 days after transplant, when they were $78\left(f_{L A G}\left(t_{L}\right)\right)$ mm in length and elongated at over $5 \mathrm{~mm} \cdot \mathrm{d}^{-1}(\gamma)$. The linear phase was estimated to end $15\left(\Delta t_{V P}\right)$ days after visible bud (or 35 days after $\left.t_{S}\right)$ at a height of $365\left(f_{L I N}\left(t_{P}\right)\right) \mathrm{mm}$, after which an additional $63 \mathrm{~mm}$ of elongation $(\delta)$ was predicted during the plateau phase.

Table 2. Analysis of variance and parameter estimates from fitting the $f_{3 \text {-phase }}$ model to the untreated control data from the calibration experiment.

\begin{tabular}{|c|c|c|c|}
\hline Source & $\mathrm{df}$ & Sum of squares & Mean square \\
\hline Regression & 4 & 13103843 & 3275961 \\
\hline Residual & 200 & 57586 & 288 \\
\hline Uncorrected total & 204 & 13161429 & \\
\hline Corrected total & 203 & 3208912 & $R^{2}=0.996$ \\
\hline \multicolumn{2}{|c|}{ Estimated parameters } & Estimate $\pm \mathrm{ASE}^{\mathrm{z}}$ & Units \\
\hline \multicolumn{2}{|l|}{$\beta$} & $0.154 \pm 0.003$ & per day \\
\hline \multicolumn{2}{|l|}{$\gamma$} & $5.36 \pm 0.10$ & $\mathrm{~mm} \cdot \mathrm{d}^{-1}$ \\
\hline \multicolumn{2}{|l|}{$\Delta t_{V P}$} & $15.4 \pm 3.1$ & days \\
\hline \multicolumn{2}{|l|}{$\delta$} & $63 \pm 20$ & $\mathrm{~mm}$ \\
\hline \multicolumn{4}{|l|}{ Observed factors } \\
\hline \multicolumn{2}{|l|}{$\alpha$} & $43 \pm 14$ & $\mathrm{~mm}$ \\
\hline \multicolumn{4}{|l|}{ Calculated factors } \\
\hline \multicolumn{2}{|l|}{$t_{L}$} & 23.1 & days \\
\hline \multicolumn{2}{|l|}{$t_{P}^{L}$} & 76.5 & days \\
\hline \multicolumn{2}{|l|}{$f_{L A G}\left(t_{L}\right)$} & 78 & $\mathrm{~mm}$ \\
\hline \multicolumn{2}{|l|}{$f_{L I N}\left(t_{P}\right)$} & 365 & $\mathrm{~mm}$ \\
\hline \multicolumn{2}{|l|}{$k_{P L A}$} & 0.0852 & per day \\
\hline \multicolumn{2}{|l|}{$H_{f}^{T-A}$} & 427 & $\mathrm{~mm}$ \\
\hline
\end{tabular}

${ }_{\mathrm{z}}^{\mathrm{ASE}}=$ asymptotic standard error. 
Growth retardant treatments. There was a statistically significant effect $(P=0.0005)$ of growth retardant concentration on elongation after $t_{e v}$, and height decreased with increasing chlormequat concentration with a range from $289 \pm 15 \mathrm{~mm}$ for the control plants to $236 \pm 17 \mathrm{~mm}$ at $4000 \mathrm{ppm}$. Growth retardant applications did not affect timing of visible bud, first color, or anthesis (which averaged 20.1 $\pm 0.1\left(\Delta t_{S V}\right), 16.1 \pm 0.4$, and 50.7 \pm 0.7 days, respectively, after the start of short days on day 41). Final leaf count (average $25.7 \pm 0.2$ leaves) was also not affected by growth retardant concentration.

Fitting the $g(t)$ dose response models. We found that estimating $\beta$ separately for each treatment improved fitting of the dose response functions because this ensured that predicted and observed height were very similar (within $5 \mathrm{~mm}$ ) at time $t_{e v}$. Elongation that occurred before growth retardants were applied at $t_{e v}$ was not significantly different between treatments (data not shown). However, we found that the Larsen and Lieth (1993) protocol for fitting the $g(t)$ models using SAS PROC NLIN was highly sensitive to even slight differences between observed and predicted height at $t_{e v}$. Estimating $\beta$ by treatment did not affect predicted elongation rate after $t_{e v}$ because in all cases, $t_{L}$, the start of the linear phase, was estimated to occur before $t_{e v}$ and $\gamma, \Delta t_{V P}$, and $\delta$ were assumed equal to the estimates from control data. Estimates of $\beta$ were $0.154 \pm 0.003,0.141 \pm 0.001,0.156 \pm 0.002,0.164 \pm 0.002$, $0.155 \pm 0.003,0.176 \pm 0.004$, and $0.153 \pm 0.003$ per day (estimate \pm asymptotic standard error) for the control, 500, 1000, 1500, 2000, 3000, and 4000 ppm treatments respectively.
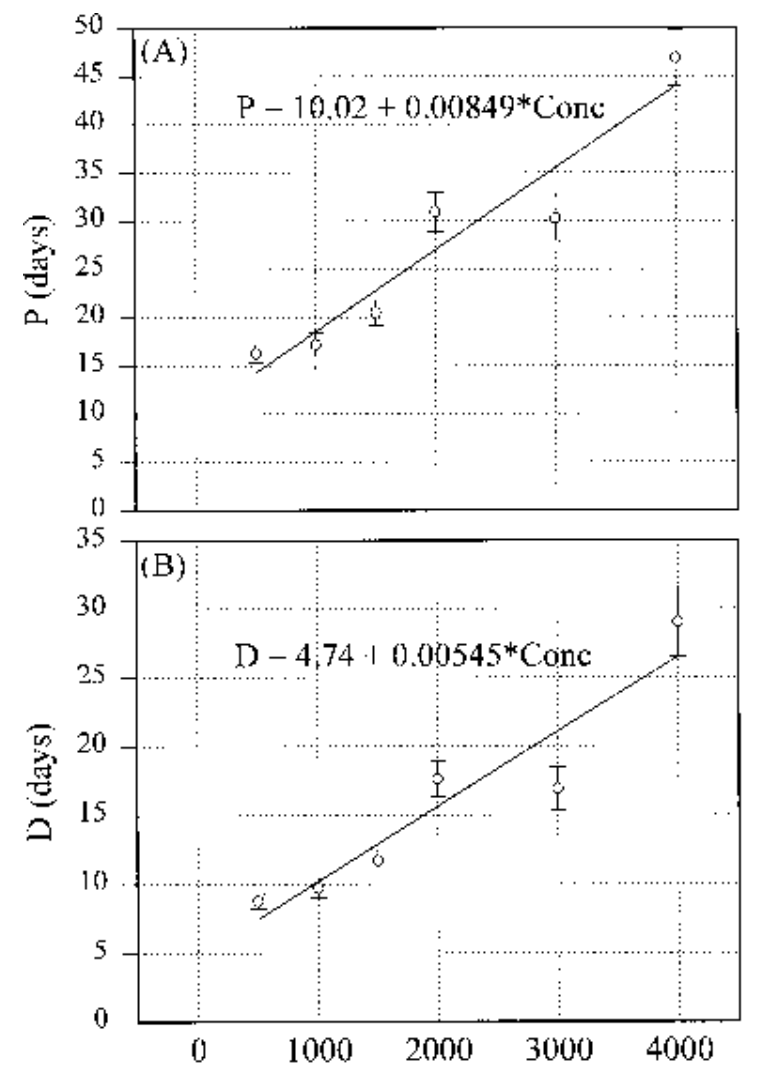

Fig. 3. Parameter estimates $(O)$ for (a) the persistence $P$ in the linear $g(t)$ model and (b) the duration parameter $D$ in the exponential $g(t)$ models respectively. The solid lines represent the linear regression (Eq. [13]) fit to the parameter estimates where the parameter $a$ represents the $y$-intercept constant and $b$ represents the gradient constant.
Table 3. Estimates of $a$ and $b$ used to calculate persistence $P$ and duration $D$ parameters in the $g_{L}(t)$ and $g_{E}(t)$ models respectively.

\begin{tabular}{lcc}
\hline \hline & $g_{L}(t)($ Linear model $)$ & $g_{E}(t)$ (Exponential model $)$ \\
\hline Amplitude & $M_{L}=0.53$ & $M_{E}=0.53$ \\
$a$ (days) & $10.558 \pm 1.278$ & $5.523 \pm 0.784$ \\
$b$ (days/ppm) & $0.00824 \pm 0.0006$ & $0.00493 \pm 0.0004$ \\
$R^{2}$ & 0.989 & 0.989 \\
\hline
\end{tabular}

We found a high degree of correlation between amplitude $\left(M_{L}\right.$ and $M_{E}$ for Eqs. [4] and [12] respectively) and duration parameters $P$ and $D$ when fitting the $g(t)$ functions to the treated plants. Estimating both the amplitude and recovery parameters by nonlinear regression was therefore not a reliable method for modeling the dose response.

Because of correlation between amplitude and duration parameters, we chose to set amplitude parameters $\left(M_{E}\right.$ and $\left.M_{L}\right)$ to a constant $(0.53)$ based on observed elongation immediately after $t_{e v}$. Growth retardant treatments elongated an average $53 \%$ as rapidly during the first day after application compared with the control (3.5 $\pm 0.5 \mathrm{~mm}$ and $6.6 \pm 0.8 \mathrm{~mm}$ respectively, $P=0.027)$. Chlormequat concentration between 500 and 4000 ppm did not, however, significantly affect initial elongation (3.6 $\pm 1.6,2.8 \pm 1.2,4.8 \pm 1.0$, $2.8 \pm 0.9,3.8 \pm 1.2$, and $3.0 \pm 1.0 \mathrm{~mm}$ for $500,1000,1500,2000$, 3000 , and $4000 \mathrm{ppm}$ respectively). We assumed that the main effect of growth retardant concentration was to increase the duration of effect $(P$ and $D)$, and we estimated $P$ and $D$ by nonlinear regression.

Both $g(t)$ models were fitted to each concentration to obtain a data set of estimates of $P$ and $D$ (Fig. 3). Both $P$ and $D$ increased with increasing chlormequat concentration between 500 and 4000 ppm. For example, the growth retardant effect was predicted to persist for 16 days at $500 \mathrm{ppm}$ and 47 days at $4000 \mathrm{ppm}$ by the linear $g_{L}(t)$ model. Parameters $P$ and $D$ were modeled as a linear function of concentration using the equation

$X=a+b \times$ Concn

where $X$ represents $P$ or $D$ for the $g_{L}(t)$ and $g_{E}(t)$ models respectively, and Conc was the chlormequat concentration in ppm. $a$ and $b$ have units of days and days/ppm respectively

Initial estimates of parameters $a$ and $b$ in Eq. [13] were calculated from linear regression of the estimated $P$ and $D$ parameters versus concentration (Fig. 3). The resulting estimates were used as starting values for fitting the $g_{L}(t)$ and $g_{E}(t)$ models separately to the entire data set of treated plants in order to estimate $a$ and $b$ by nonlinear regression. Of the remaining parameters in the complete $G_{L}$ and $G_{M}$ models, the amplitude parameters $\left(M_{L}\right.$ and $\left.M_{E}\right)$ were set to 0.53 , based on observed elongation rate between $t_{e v}$ and $t_{e v}+1$; the $f_{3-p h a s e}$ model parameters $\gamma, \Delta t_{V P}$, and $\delta$ were set to the estimates for the untreated control plants (Table 2) and $\beta$ was set to the value previously estimated for each treatment.

The resulting two $g(t)$ models (Table 3 ) both had an $R^{2}$ of 0.989 , and the coefficient of variation of parameter estimates was also similar. At $1500 \mathrm{ppm}$, the $g_{L}(t)$ model predicted greater growthretarding effect than the $g_{E}(t)$ model during the first 18 days after $t_{e v}$ (Fig. 4a), whereas the $g_{E}(t)$ model predicted greater growth retarding effect as the $g_{L}(t)$ model neared 1 . The relative growthretarding $(g(t))$ effect predicted by the models never differed by more than 0.1 for all concentrations between 500 and 4000 ppm and all days after application (Fig. 4a). The $g_{L}(t)$ model predicted that a 500 ppm growth retardant applied 34 days after transplant would persist for 15 days and reduce height by $6 \%$ compared with an untreated plant (Fig. 4b); at 4000 ppm persistence would be 44 

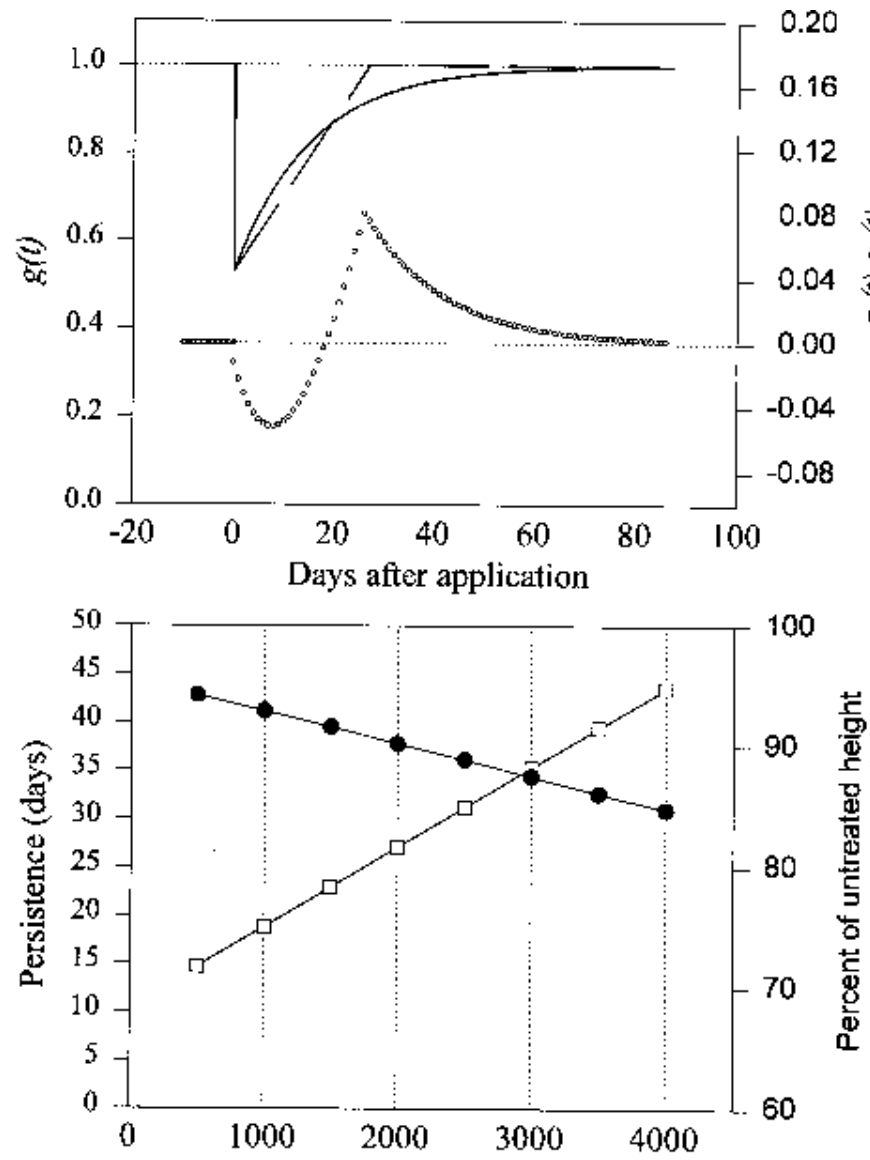

Chlormequat concentration (ppm)

Fig. 4. (a) Comparison of $g_{L}(t)$ (dashed line) and $g_{E}(t)$ (solid line) dose response models assuming a $1500 \mathrm{ppm}$ chlormequat application, $\mathrm{O}=$ difference between models $\left(g_{L}(t)\right.$ minus $\left.g_{E}(t)\right)$. (b) Final height of chlormequat-treated plants relative to that of untreated plants for a growth retardant applied $t_{e v}=34$ days after transplant $(\bullet)$, and growth retardant persistence for various concentrations (Conc) using the $g_{L}(t)$ model ( $\square$ ).

days and height reduction $15 \%$. There was little difference between the predictions of the $G_{L}$ model and those of the $G_{M}$ model, and at a given chlormequat concentration the final heights predicted by both models were within $3 \mathrm{~mm}$, or $1 \%$ (the $G_{L}$ model predicting slightly more elongation). Predictions by both models were within $9 \mathrm{~mm}$ of the average final height for each treatment, with the greatest deviation for the 2000 ppm treatment (Figs. 5 and 6).

Model validation. The $f_{3-\text { phase }}$ function was fitted to the untreated control plants (Table 4, Fig. 7a) in the validation experiment. The control plants elongated more rapidly during the lag phase compared with the control plants in the calibration experiment, with a significantly higher estimate of $\beta$ and an earlier estimate of $t_{L}$. Elongation of the untreated validation plants was $26 \%$ slower during the linear phase compared with the calibration experiment. However, validation experiment transplants were $7 \mathrm{~cm}$ longer than the calibration cuttings. Therefore, although total predicted final height $\left(H_{f}\right)$ of the control plants was only $3 \mathrm{~cm}$ shorter in the validation experiment compared with the calibration experiment, validation plants were $10 \mathrm{~cm}$ shorter when only elongation after transplant was considered. The estimate of $\delta(21 \pm 19 \mathrm{~mm})$ had a high asymptotic standard error, which was probably because few data points were collected from the plateau phase. The $\delta$ parameter for the validation plants was estimated to be only one-third of the length of the plateau in the calibration experiment, in part because
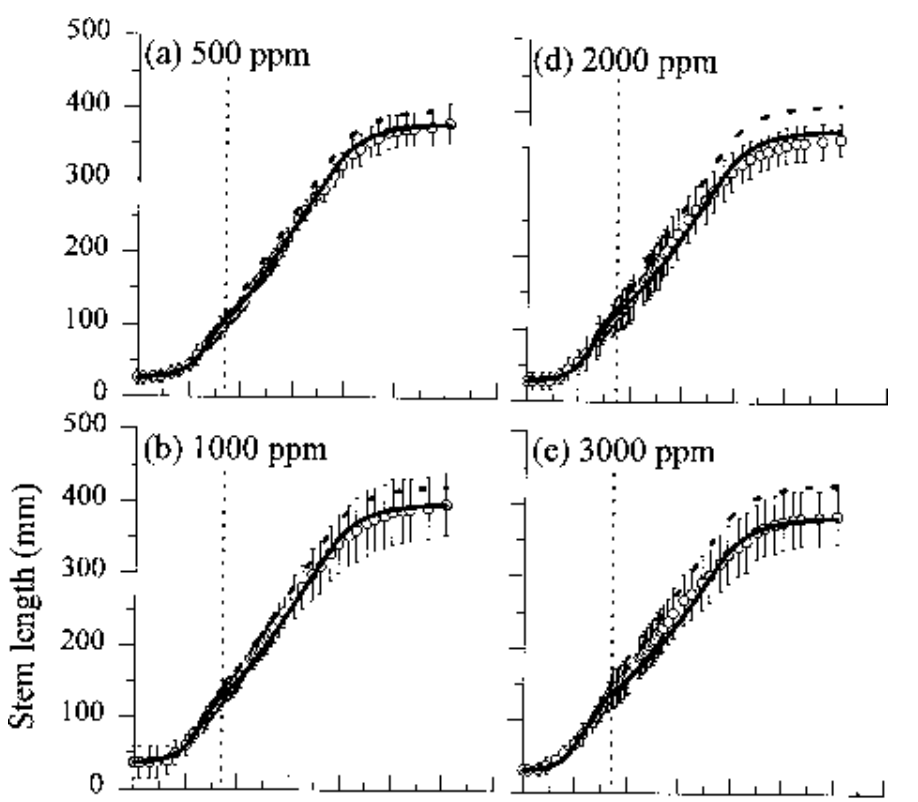

7 (e) $3000 \mathrm{ppm}$
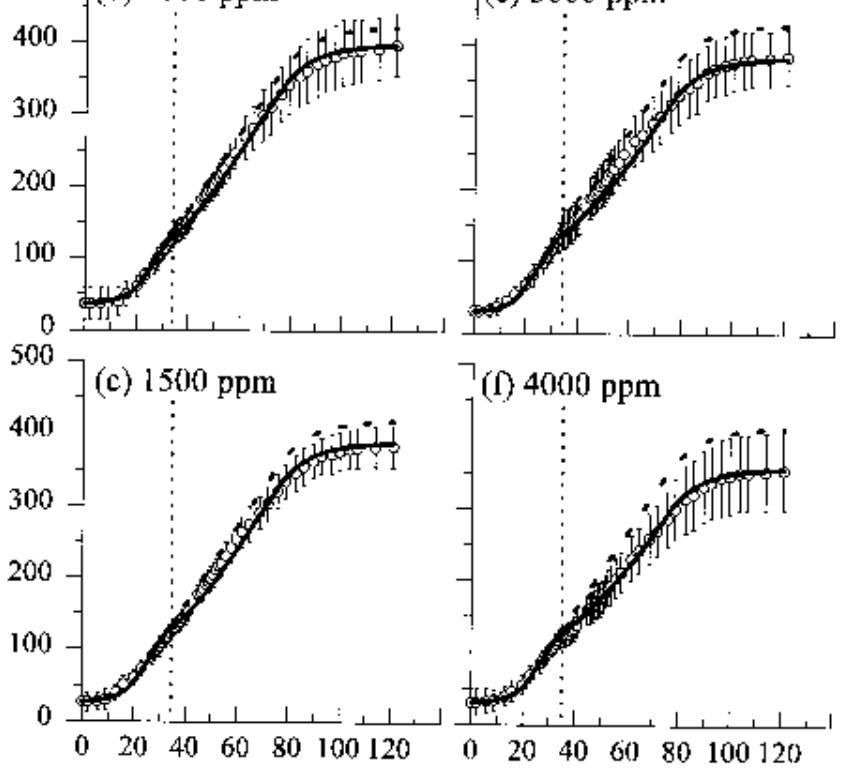

Days after transplant

Fig. 5. (a-f) Plot of observed average stem length (O) for growth retardant treatments over time during the calibration experiment and predicted height from the exponential $g_{E}(t)$ model (solid line). The dashed line represents heights predicted by the $f_{3-\text { phase }}$ model in the absence of a growth retardant application.

the estimate of $\Delta t_{V P}$ was 9 days later than that in the calibration experiment.

Heights were predicted for the growth retardant-treated plants using the $g(t)$ models (Table 3 ) from the calibration experiment combined with the $f_{\text {3-phase }}$ parameters from the untreated validation plants (Table 4), simulating with a 0.5 -d time step. The estimates of $\beta$ were not significantly different between growth retardant treatments, and the estimate of $\beta$ for untreated control plants was used in all cases. The height predicted by $G_{L}$ (not displayed) and $G_{E}$ models (Fig. $7 \mathrm{~b}-\mathrm{d}$ ) closely tracked the observed height $\left(r^{2}=0.967\right)$ and was always within the $95 \%$ confidence intervals. However, both models overpredicted final height of the growth retardanttreated plants, by 3,9 , and $8 \mathrm{~mm}\left(G_{E}\right.$ model $)$ for the 1000,2000 , and $3000 \mathrm{ppm}$, respectively, and by 6,12 , and $11 \mathrm{~mm}\left(G_{L}\right.$ model $)$.

\section{Discussion}

The untreated control plants exhibited a three-phase elongation pattern in both experiments. However, between years there were differences in the length of each phase and the elongation rate. Validation control plants elongated $10 \mathrm{~cm}$ less after transplant than the calibration plants. Flower-initiating nyctoperiods were begun five days earlier in the validation experiment than in the calibration experiment, and the $f_{3-\text { phase }}$ model would predict about $26 \mathrm{~mm}$ less 


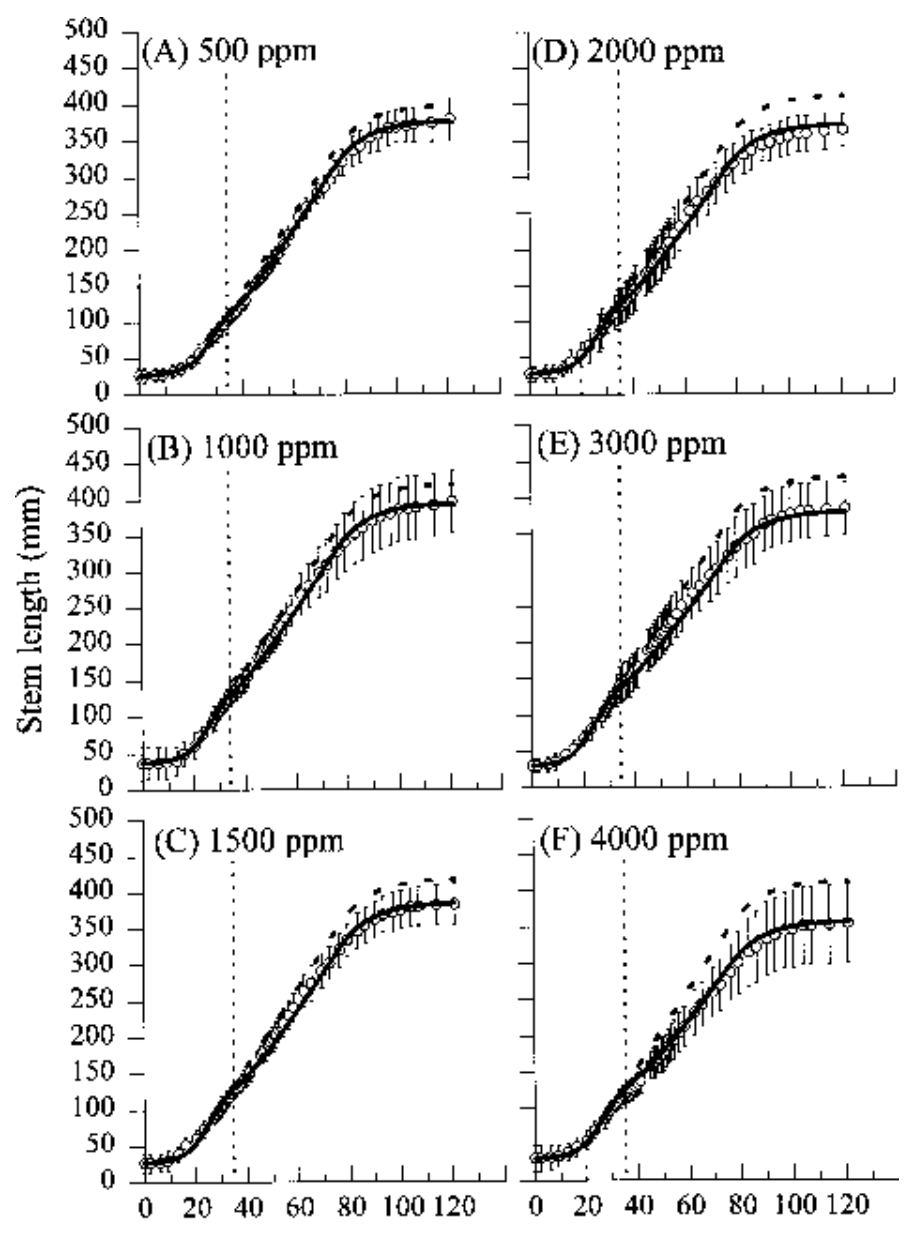

Days after transplant

Fig. 6. (a-f) Plot of observed average stem length for growth retardant treatments over time during the calibration experiment $(\bigcirc)$ and predicted height from the linear $g_{L}(t)$ model (solid line).

elongation in the validation experiment, based on the effect of flower-initiation date described by Fisher et al. (1996). DIF temperature was $1{ }^{\circ} \mathrm{C}$ lower during the validation experiment, which would also have slightly reduced elongation (Berghage and Heins, 1991). Differences in transplant size and vigor also may have affected elongation. Few data were collected during the plateau phase in the validation experiment, and plants may have elongated more than estimated.

The dose response $g(t)$ models are highly empirical. In the equation describing the effect of chlormequat concentration on duration of effect (Eq. [13]), $a$ represents the intercept or duration when concentration Conc $=0$, and $b$ represents the effect on duration of increasing Conc. Because $a$ does not equal zero duration at $C o n c=0$, the model should not be extrapolated beyond concentrations of 500 to $4000 \mathrm{ppm}$. The model predicts that initial retarding effect is independent of concentration between 500 to 4000 ppm: for all concentrations in this range, the maximum growth retarding effect is predicted to be $53 \%$ of the untreated control.

This type of experiment and methodology does not effectively identify the most biologically valid or mechanistic formulation of $g(t)$. In Larsen and Lieth's (1993) research on daminozide applications to chrysanthemum, $g_{L}(t)$ and $g_{E}(t)$ equations resulted in a close fit to observed data. The researchers noted close correlation of amplitude and recovery factors, a similar effect on absolute growth rate of the two $g(t)$ models, variability in data, and a lack of knowledge of the physiology of daminozide activity. As a result, although their methodology was an effective empirical model, Larsen and Lieth (1993) noted that it was less effective at selecting the most biologically valid form of $g(t)$. The most appropriate form of $g(t)$ is likely to vary depending on chemical type, translocation pathway, and plant species. Either Larsen and Lieth (1993) $g(t)$ model may be appropriate for daminozide on chrysanthemum, because translocation and activity are rapid (Dicks, 1972) and the effect declines over time (Dicks, 1972; Dicks and Charles-Edwards, 1973; Tayama and Carver, 1992).

Increased knowledge of growth retardant physiology would be necessary to develop a more mechanistic model. Chlormequat primarily retards height by inhibiting internode elongation (Steffens, 1980), although the chemical inhibited subapical cell expansion and division in chrysanthemum, and promoted transverse stem growth, resulting in short, thick stems (Sachs and Kofranek, 1963). The principal mechanism of action for chlormequat has been associated with the inhibition of gibberellin biosynthesis resulting in a reduction in the endogenous content of gibberellins (Grossman, 1992). Effects on gibberellin activity, IAA metabolism, ethylene production, and sterol synthesis also may be involved, however (Steffens, 1980).

Chlormequat is absorbed rapidly, with more than $90 \%$ of ${ }^{14} \mathrm{C}$ labeled chemical applied to a wheat leaf being taken up within 24 h (Arissian et al., 1991). Rapid absorption supports the $g(t)$ assumption of immediate growth-retarding effect after $t_{e v}$. Chlormequat has been described as readily translocated in the xylem and phloem and is highly water-soluble (Krishnamoorthy, 1981; Smith et al., 1982). However, Arissian et al. (1991) found that over $85 \%$ of the chemical remained in a treated wheat leaf 10 days after a foliar application. This result suggests that as a plant elongates over time, the zones of cell division and elongation may become physically distant from the original application sites that contain the highest concentration of chlormequat.

Table 4. Analysis of variance and parameter estimates from fitting the $f_{3-p h a s e}$ model to the untreated control data from the validation experiment.

\begin{tabular}{|c|c|c|c|}
\hline Source & $\mathrm{df}$ & Sum of squares & Mean square \\
\hline$\overline{\text { Regression }}$ & 4 & 17817477 & 4454369 \\
\hline Residual & 320 & 40502 & 127 \\
\hline Uncorrected total & 324 & 17857979 & \\
\hline Corrected total & 323 & 2138957 & $R^{2}=0.997$ \\
\hline \multicolumn{2}{|c|}{ Estimated parameters } & Estimate $\pm \mathrm{ASE}^{\mathrm{z}}$ & Units \\
\hline \multicolumn{2}{|l|}{$\beta$} & $0.169 \pm 0.003$ & per day \\
\hline \multicolumn{2}{|l|}{$\gamma$} & $3.95 \pm 0.44$ & $\mathrm{~mm} \cdot \mathrm{d}^{-1}$ \\
\hline \multicolumn{2}{|l|}{$\Delta t_{V P}$} & $24.4 \pm 3.6$ & days \\
\hline \multicolumn{2}{|l|}{$\delta$} & $21 \pm 19$ & $\mathrm{~mm}$ \\
\hline \multicolumn{4}{|l|}{ Observed factors } \\
\hline \multicolumn{2}{|l|}{$\alpha$} & $110 \pm 11$ & $\mathrm{~mm}$ \\
\hline \multicolumn{4}{|l|}{ Calculated factors } \\
\hline \multicolumn{2}{|l|}{$t_{L}$} & 18.6 & days \\
\hline \multicolumn{2}{|l|}{$t_{P}^{L}$} & 79.9 & days \\
\hline \multicolumn{2}{|l|}{$f_{L A G}\left(t_{L}\right)$} & 133 & $\mathrm{~mm}$ \\
\hline \multicolumn{2}{|l|}{$f_{L I N}\left(t_{P}\right)$} & 375 & $\mathrm{~mm}$ \\
\hline \multicolumn{2}{|l|}{$k_{P L A}$} & 0.186 & per day \\
\hline \multicolumn{2}{|l|}{$H_{f}$} & 396 & $\mathrm{~mm}$ \\
\hline
\end{tabular}




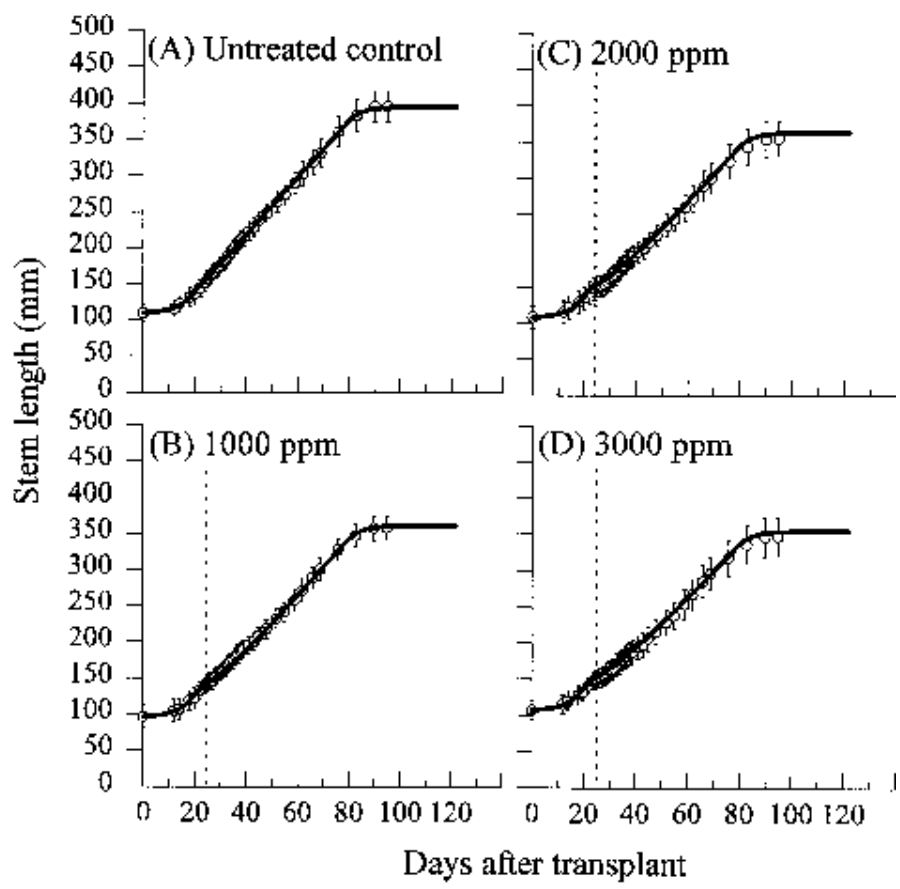

Fig. 7. (a-d). Plot of the validation data set showing observed average stem length for control and growth retardant treatments over time $(O)$ and predicted height from the exponential $g(t)$ model combined with the $f_{3-p h a s e}$ function fit to the untreated validation control plants (solid line).

Smith et al. (1982) reviewed research on the rate of degradation of chlormequat chloride and found contradictory evidence. Some research suggested rapid degradation (for example, 20\% to 30\% metabolism within $24 \mathrm{~h}$ in barley and chrysanthemum shoots (Schneider, 1967)) whereas other reports indicated that the compound may be stable in wheat plants for four or more weeks after application. Decomposition rate of chlormequat is affected by temperature, with little decomposition below $4^{\circ} \mathrm{C}$ or above $40^{\circ} \mathrm{C}$, and the chemical is broken down by soil microorganisms if applied as a drench (Steffens, 1980). Growth-retarding activity may not simply decline as metabolism of chlormequat increases. Smith et al. (1982) suggested the possibility that the growth effects attributed to the parent compound may occur as a result of a combination or balance of parent compound and metabolites.

We chose the $g(t)$ models based on achieving the desired empirical qualities for the intended use of the model. The initial amplitude $M_{L}$ or $M_{E}$ can be approximated as the observed reduction in elongation immediately after $t_{e v}$, whereas $P$ and $D$ must be estimated by nonlinear regression. Data were highly variable within growth retardant treatments when examined over short periods; for example, the first one to three days after $t_{e v}$. However, a statistical comparison of initial elongation did not indicate that initial elongation rate was affected by concentrations between 500 and $4000 \mathrm{ppm}$. When we used nonlinear regression to estimate $M_{L}$ or $M_{E}$ in addition to the duration equation (Eq. [13]), the amplitude estimates were $0.75 \pm 0.01$ ( \pm asymptotic standard error) and 0.71 \pm 0.02 for the $G_{L}$ and $G_{E}$ models, respectively. Although the resulting models overall had a slightly higher $R^{2}(0.990)$ than the $G_{L}$ and $G_{E}$ models in Table 3, the predicted heights during the first 10 days after application did not fit as well to observed data, especially in the validation experiment. Using nonlinear regression to estimate amplitude therefore less effectively predicted short-term effects of chlormequat, which was our primary intended use of the model, than assuming a $47 \%$ initial reduction.

The resulting model closely fit the observed data during calibra- tion and validation trials. Further validation of this model would be necessary to incorporate variables that are important in commercial horticulture. Effect of plant pinching, cultivar, average and DIF temperatures, date and method of application, and number of applications should be considered. Several other growth retardants are applied to poinsettia (Ecke et al., 1990), including ancymidol, daminozide (applied in combination with chlormequat), paclobutrazol, and uniconazole. Therefore, a comprehensive growth retardant dose response model would need to make considerable simplifying assumptions to accommodate this large combination of possible situations. The model could be used to aid heightcontrol decisions, by predicting the final effect of a single foliar application of chlormequat on percent height reduction (Fig. 4b) and dynamically simulating the effect of a proposed or actual application on elongation over time.

\section{Literature Cited}

Arissian, M., D. Perrissin-Fabert, A. Blouet, J. Morel, and A. Guckert. 1991. Effect of imazaquin on absorption, translocation, and pattern of distribution of chlormequat chloride in winter wheat. J. Plant Growth Regulat. 10:1-4.

Barrett, J.E. 1982. Chrysanthemum height control by ancymidol, PP333, and EL-500 dependent on medium composition. HortScience 17:896-897.

Berghage, R.D. and R.D. Heins. 1991. Quantification of temperature effects on stem elongation in poinsettia. J. Amer. Soc. Hort. Sci. 116:14-18.

Dicks, J.W. 1972. Uptake and distribution of the growth retardant, aminozide, in relation to control of lateral shoot elongation in Chrysanthemum morifolium. Ann. Appl. Biol. 72: 313-326.

Dicks, J.W. and D.A. Charles-Edwards. 1973. A quantitative description of inhibition of stem growth in vegetative lateral shoots of Chrysanthemum morifolium by $\mathrm{N}$ Dimethylaminosuccinamic acid (Daminozide). Planta 112:71-82.

Ecke, P., O.A. Matkin, and D.E. Hartley. 1990. The poinsettia manual. 3rd ed. Paul Ecke Publications, Encinitas, Calif.

Fisher, P.R., R.D. Heins, and J.H. Lieth. 1996. Quantification of the relationship between phases of stem elongation and flower initiation in poinsettia. J. Amer. Soc. Hort. Sci. (In press.)

Gilbertz, D.A. 1992. Chrysanthemum response to timing of paclobutrazol and uniconazole sprays. HortScience 27:322-323

Grossman, K. 1992. Plant growth retardants: Their mode of action and benefit for physiological research, p. 788-797. In: C.M. Karssen, L.C. von Loon, and D. Vreugdenhil (eds.). Progress in plant growth regulation, Kluwer, Netherlands.

Holcomb, E.J., L. Gohn, and J.C. Shriver. 1992. 1991 poinsettia trials: Fertigation and growth retardant trials. Pennsylvania Flower Growers Bul. 411.

Holcomb, E.J. and M. Rose. 1992. Poinsettia height reduction using multiple applications of Sumagic. Pennsylvania Flower Growers Bul. 413.

Krishnamoorthy, H.N. 1981. Plant growth substances. McGraw-Hill, New Delhi

Larsen, R.U. and J.H. Lieth. 1993. Shoot elongation retardation owing to daminozide in chrysanthemum: I. Modeling single applications. Scientia Hort. 53:109-125.

Larson, R.A. 1967. Chemical growth regulators and their effects on poinsettia height control. North Carolina Agr. Expt. Sta. Tech. Bul. 180.

Lieth, J.H. and J.F. Reynolds. 1986. Plant growth analysis of discontinuous growth data: A modified Richards function. Scientia Hort. 28:301-304.

Ludolph, D. 1992. Height control of ornamental plants without chemical growth retardants. Ohio Florists Assn. Bul. 748:1-4.

McDaniel, G.L. 1986. Comparison of paclobutrazol, flurprimidol, and tetcyclasis for controlling poinsettia height. HortScience 21:1161-1163.

McDaniel, G.L. and S. Wilson. 1990. Comparison of split application vs. single rate application of uniconazole on poinsettia. Tennessee Farm Home Sci. 155:11-15.

Richards, F.J. 1959. A flexible function for experimental use. J. Expt. Bot. 10:290-300.

Sachs, R.M. and A.M. Kofranek. 1963. Comparative cytohistological studies on inhibition and promotion of stem growth in Chrysanthemum morifolium. Amer. J. Bot. 50:772-779.

Statistical Analysis Systems Institute. 1988. SAS/STAT users guide, version 6.03. SAS Institute, Cary, N.C.

Schneider, E.F. 1967. Conversion of the plant growth retardant (2-chloroethyl) trimethyl ammonium chloride to choline in shoots of chrysanthemum and barley. Can. J. Biochem. 45:395-400.

Smith, A.R., T.H. Thomas, and J.F. Garrod. 1982. Specificity and mode of action of BTS 44584 and chlormequat chloride in wheat and soybeans: II. Distribution and persistence. Ann. Applied Biol. 101:349-357.

Steffens, G.L. 1980. Applied uses of growth substances-Growth inhibitors, p. 397-408. In: F. Skoog (ed.). Plant growth substances 1979. Springer-Verlag, Berlin.

Tayama, H.K. and S.A. Carver. 1992. Residual efficacy of Uniconazole and Daminozide on potted 'Bright Golden Anne' chrysanthemum. HortScience 27:124-125. 